\title{
Using acoustic emission to characterize friction and wear in dry sliding
}

\section{steel contacts}

\author{
Zhe Geng ${ }^{\mathrm{a}}$ Debashis Puhan ${ }^{\mathrm{b}}$ Tom Reddyhoff ${ }^{\mathrm{b}}$ \\ aDepartment of Precision Manufacturing Engineering, Suzhou Institute of Industrial Technology, \\ Suzhou, 215104, PR China \\ ${ }^{\mathrm{b}}$ Tribology Group, Department of Mechanical Engineering, Imperial College London, Exhibition \\ Road, SW7 2AZ, London, United Kingdom
}

Received 31 October 2018, Revised 2 February 2019, Accepted 8 February 2019, Available online 14 February 2019.

\begin{abstract}
Acoustic emission (AE) was recorded during tribological tests on 52100 steel specimens under different loads. AE signals were transformed to the frequency domain using a Fast Fourier Transform and parameters such as power, RMS amplitude, mean frequency, and energy were analyzed and compared with friction coefficient and wear volume measurements. Results show that certain acoustic frequencies reflect friction while others reflect wear. If frequencies are chosen optimally, AE and friction signals are highly correlated (Pearson coefficients $>0.8$ ). SEM and Raman analysis reveal how plastic deformation and oxide formation affect friction, wear and $\mathrm{AE}$ simultaneously. AE recordings contains more information than conventional friction and wear volume measurements and are more sensitive to changes in wear mechanism. This all demonstrates AE's potential as a tool to monitor tribological behavior.
\end{abstract}

Keywords: Acoustic emission, friction, wear, monitoring, steel.

\section{Introduction}

Machine failures typically occur at the interfaces between sliding components [1] and there is an increasing need to be able to monitor these in order to reduce costly downtime and needless maintenance [2]. This is particularly the case in vehicles due to extended service intervals and oil-for-life being implemented in hybrids. Acoustics emission (AE) is emerging as a promising means of on-line sensing, which has been proposed to monitor the operating status of bearings [3], cutting tools [4], head/disk interfaces [5], surface finishing processes [6], grinding wheels [7] and rotating machines $[8,9]$. This is largely because $\mathrm{AE}$ transducers can be located remotely from the interface being monitored, they require no optical window and can detect the transient elastic stress waves which result from elastic/plastic deformation and fracture accompanying friction and wear [10].

There are many AE signals parameters that may be analyzed to obtain tribological information. In the time domain, $\mathrm{AE}$ counts, amplitude, duration and root mean squared (RMS) AE are commonly used due to the simple and intuitive acquisition of these parameters. For instance, in certain pin-on-disc tests, $\mathrm{AE}$ event counting rates were found to increase with wear rate, coefficient of friction $(\mathrm{CoF})$ and microgroove depth [11]. AE event counting rates were also observed to increase with sliding velocity [12] and wear particle count [13]. The amplitude and duration of an $\mathrm{AE}$ 
waveform can correlate with the quantity of wear particles, as does the AE energy [14]. Moreover, the amplitude and length of a train of $\mathrm{AE}$ waves can be associated with individual slip events during the stick-slip [15]. In addition to this, the AE event location can determin mode I crack propagation in fretting fatigue [16]. The instantaneous RMS amplitude has been found to correlate with CoF [17-19], distinguish between different stages in CoF evolution [20] and even predict CoF based on a power law relation [18]. AE RMS can also be sensitive to applied load, velocity and mechanical properties of sliding components [20]. The integrated AE RMS can be related to frictional work and wear under different sliding speeds [18] and loads [21] and can detect the sliding speed threshold for accelerated wear [18]. The integrated AE RMS [22, 23] may also have a direct correlation with the wear volume and wear rate [24].

In the frequency domain, AE parameters such as energy and median frequency (MDF) can be used, with the former being correlated to $\operatorname{CoF}[25,26]$ and wear volume [27] and the latter being correlated to $\mathrm{CoF}[26,28]$ and frictional work [29]. The amplitude of individual AE frequency components can also be excited by specific wear mechanisms, which can be determined based on power spectral density (PSD) and auto-covariance techniques [30]. In addition to this, it has been found that low and high frequencies are associated with different lubricant conditions [28]. Peak frequencies can vary depending on wear mechanism, with adhesive wear emission suggested to occur around 1.1 MHz and abrasive wear between 0.25-1 MHz [31, 32], while stick slip results in dominant $\mathrm{AE}$ frequencies around $10 \mathrm{kHz}$ [20].

Time-frequency analysis can also be applied to AE signals, with evolving PSD spectra indicating different stages wear [19] and wavelet analysis detecting the onset of scuffing $[33,34]$ and other wear states [35] [36].

Reviewing this literature it is apparent that the instantaneous RMS value of the acquired $\mathrm{AE}$ signal has been the most widely used parameter to correlate with friction and wear [17-19, 22, 23, 37, 38]. However, recently questions have been raised regarding the suitability of relying on this approach alone $[1,39]$. And, of the many other $\mathrm{AE}$ signal parameters that can be acquired (power spectra, energy, mean frequency (MNF), median frequency (MDF) etc.) it is not obvious which is most effective in reflecting friction and wear behavior. A related issue is that physical origins of $\mathrm{AE}$ signal generation are not well understood. To address these issues, the current study systematically correlates different $\mathrm{AE}$ parameters with friction and wear measurements of steels contacts under different normal loads and the relationships between these parameters are evaluated and discussed. The worn surfaces are also analyzed using SEM and Raman to understand the role of wear mechanisms in AE signal generation.

\section{Experiments}

\subsection{Materials and test setup}

Reciprocating tribological tests were performed using a ball-on-disc High Frequency Reciprocating Rig (HFRR, PCS Instruments) (Fig. 1). The $6 \mathrm{~mm}$ diameter ball was made from AISI E-52100 steel with a hardness of 58-66 HRC and a surface roughness $R_{a}$ of less than $0.05 \mu \mathrm{m}$. The disc was made from AISI E-52100 steel machined from annealed rod, with a diameter of $10 \mathrm{~mm}$, a hardness of 190-210 HV30 and a surface roughness $R_{a}$ of less than $0.02 \mu \mathrm{m}$. The samples were ultrasonically cleaned with toluene and 2-propanol separately for $10 \mathrm{~min}$ and dried before testing. The dry sliding tests were carried out under normal loads of $0.5,1,2,3,4,6,8$ and $10 \mathrm{~N}$. The reciprocating frequency was $50 \mathrm{~Hz}$, the stroke length $1 \mathrm{~mm}$ and the duration $10 \mathrm{~min}$. The coefficient of friction 
was recorded by the test rig. Every test was repeated at least twice and the repeatability of the tests was evident. The AE sensor (Micro200HF, Mistras) was bonded with the disc holder using cyanoacrylate adhesive. This position was chosen since it was stationary and close to the contact without obstructing the reciprocating motion. Moreover, pencil break tests showed that this location provided high AE signal readings with low variance.

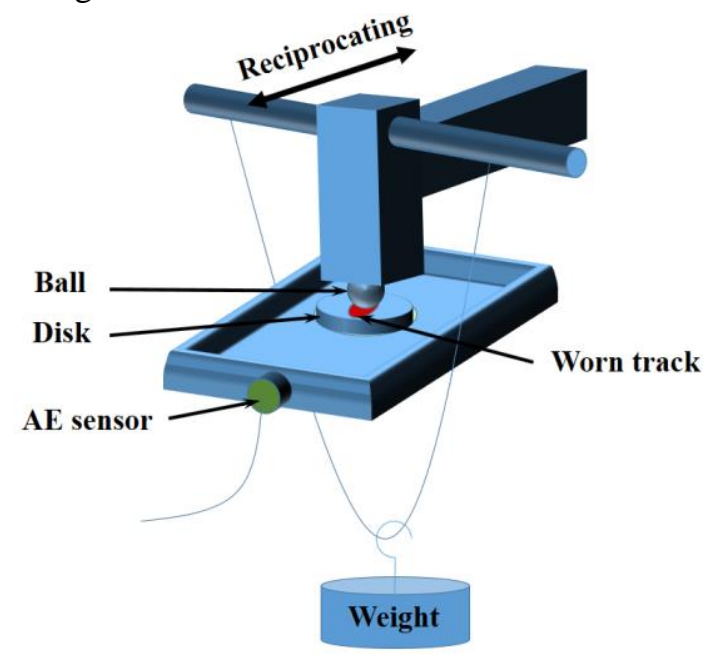

Fig. 1. Experimental setup

\subsection{AE signal acquisition and data processing}

The AE set-up consisted of a sensor, preamplifier (Mistras - 2/4/6) and a PCI-2 Analogue to Digital (A/D) card (Mistras). The analogue AE signal detected by the sensor (resonant frequency $2.5 \mathrm{MHz}$; band pass $50-4500 \mathrm{kHz}$ ) passed through the preamplifier (40 dB gain with frequency range of $10 \mathrm{kHz}-2 \mathrm{MHz}$ ) and was converted into a digital sample by the PCI- 2 card at a speed of $2 \mathrm{MHz}$. The data was acquired displayed and stored by the software AEwin (Mistras). The captured data were exported to .txt files which were imported into MATLAB for the Fast Fourier Transformation (FFT) and calculation of parameters such as RMS, Pearson coefficient, AE energy, mean frequency (MNF) and median frequency (MDF). The MNF is an average frequency which was calculated as the sum of the product of the $\mathrm{AE}$ power spectrum and the frequency divided by the total sum of the power spectrum. The MDF is the frequency which divides AE power spectrum into two regions with equal energy. Both of these AE signal characteristics have been suggested to correlate with tribological behavior $[1,26,27]$.

Fig. 2 shows an example of the approach used to process the raw time domain data. An example $1 \mathrm{~s}$ portion of the original signal containing 2,000,000 data points (Fig. 2a) was transformed to the frequency domain (Fig. 2b) by applying an FFT. This process was then repeated for every other $1 \mathrm{~s}$ portion of the acquired time signal from the test and the resulting FFTs were stacked together to form a power spectral density $v s$. time plot - i.e. a spectrogram (Fig. 2c).
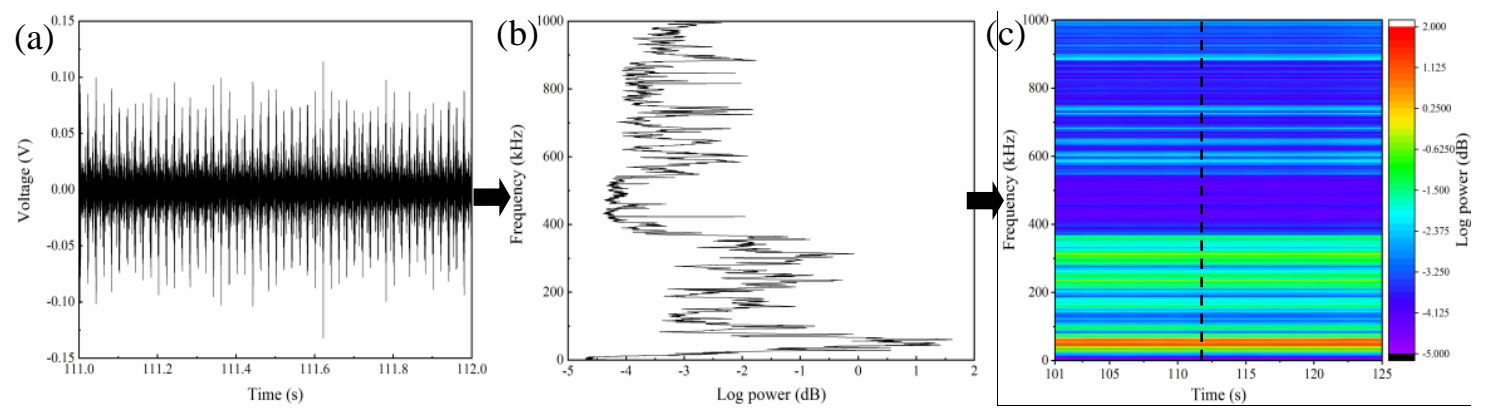
Fig. 2 AE signal data processing: (a) original $1 \mathrm{~s}$ signal in time domain; (b) frequency domain (c) power spectral density contour colour-map

\subsection{Analysis of worn surface}

The diameter of the worn surface of the ball was measured using an optical microscope (HiRox) and the wear volume was calculated using the spherical cap formula. The wear volume of the disc was measured using a white light interferometer (WLI, Veeco). Here, eight single-line traces were made across the worn surfaces. From each trace, an area of material loss caused by wear was calculated by integration. Then, the wear volume of the disc was obtained by integrating the areas of material loss along the length of the worn surface. Scanning electron microscopy (SEM, S-3400N) was employed to investigate the morphologies of the worn surfaces. The compositional analysis of the worn surfaces were made using an energy-dispersive X-ray spectrometer (EDX, Oxford). The oxide phases on the worn surface were analyzed by Raman spectroscopy using a spectrometer (WITec). The laser was focused on the sample through a 50x objective microscope with a wavelength of 514 nm.

\section{Results and discussion}

\subsection{Friction and wear characteristics}

The average steady state coefficient of friction and the total wear volume of the steel ball and disc under different loads are shown in Fig. 3. As the load increases, the coefficient of friction between ball and disc gradually decreases whilst the total wear volume increases.

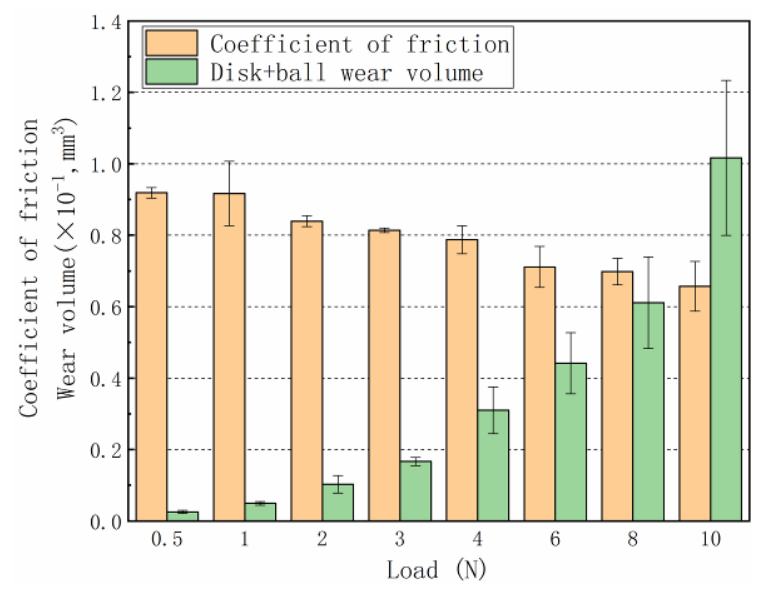

Fig. 3. Coefficient of friction and wear volume of the steel ball and disc under different loads.

\subsection{Acoustic emission and friction}

Fig. 4a-p displays the CoF evolution for each test and the corresponding spectrogram showing variation of AE power spectrum with time. The latter is produced by applying an FFT to a moving window on the AE time signal as described in Section 2.2. As the load increases, the CoF gradually decreases and becomes smooth except under $10 \mathrm{~N}$, when the fluctuation in the CoF signal increases. The spectrogram plot shows that different frequencies exhibit different trends over time. The local high intensity frequency ranges are $10-400 \mathrm{kHz}, 540-770 \mathrm{kHz}$ and $850-920 \mathrm{kHz}$ and these broaden as the load increases. 

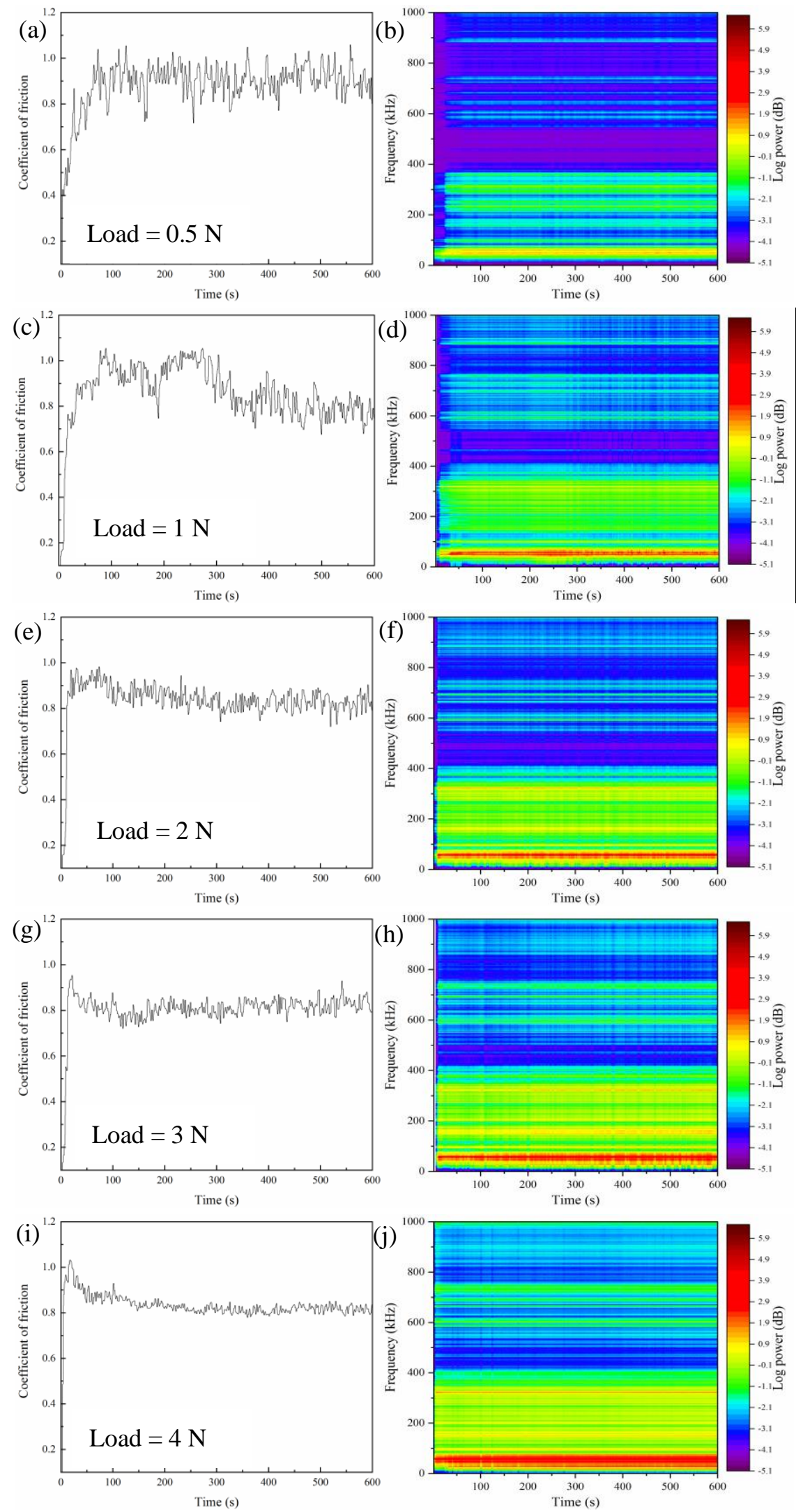

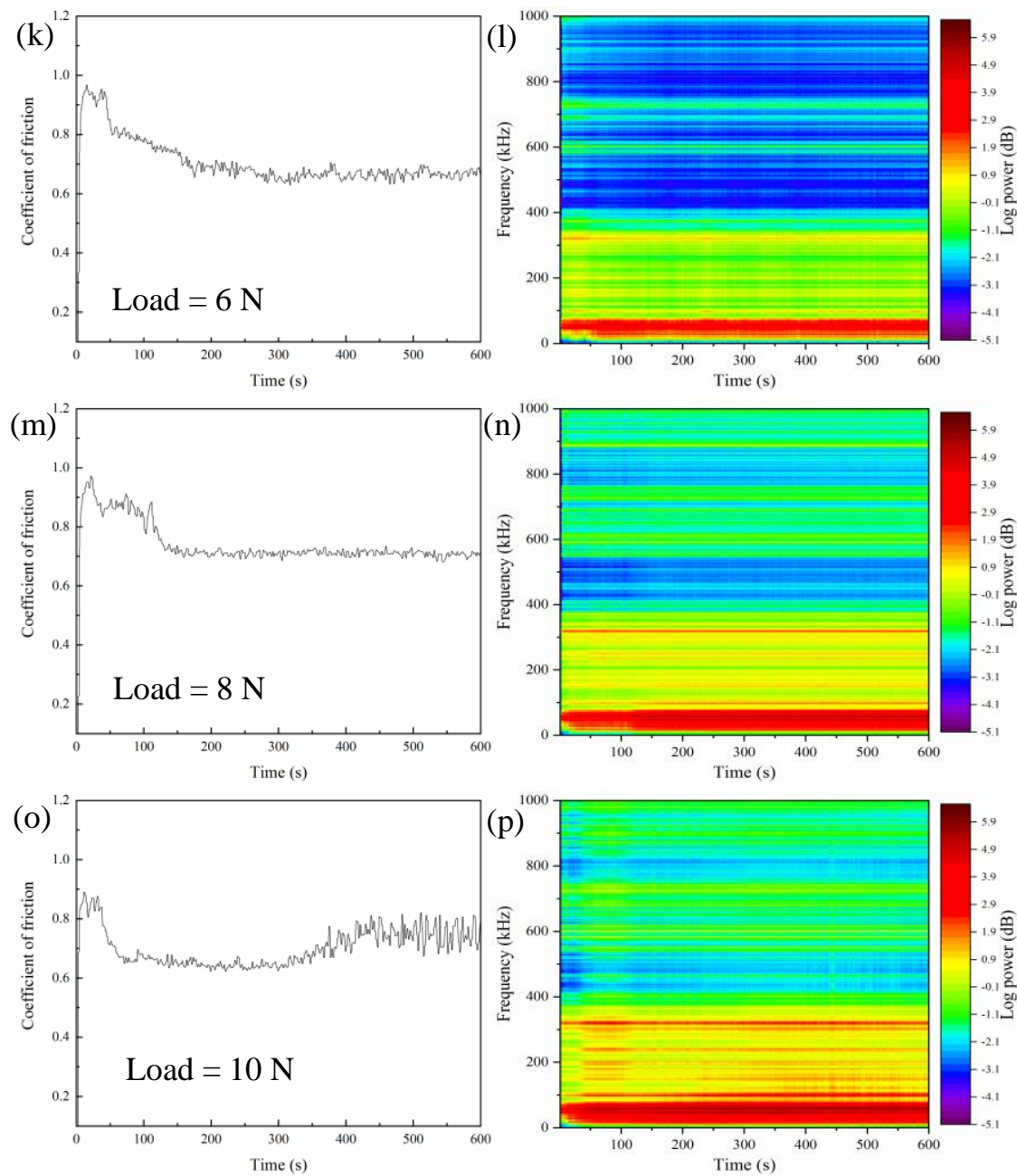

Fig. 4. Coefficient of friction $v s$. time: (a) $0.5 \mathrm{~N}$, (c) $1 \mathrm{~N}$, (e) $2 \mathrm{~N}$, (g) $3 \mathrm{~N}$, (i) $4 \mathrm{~N}$, (k) $6 \mathrm{~N}$, (m) $8 \mathrm{~N}$, (o) $10 \mathrm{~N}$, and power spectral density contour colour-maps: (b) $0.5 \mathrm{~N}$, (d) $1 \mathrm{~N}$, (f) $2 \mathrm{~N}$, (h) $3 \mathrm{~N}$, (j) $4 \mathrm{~N}$, (l) $6 \mathrm{~N}$, (n) $8 \mathrm{~N}$, (p) $10 \mathrm{~N}$.

The question arises: are some $\mathrm{AE}$ frequencies better than others at reflecting friction behavior and if so which frequency are best? To answer this, Fig. 5 shows the AE spectrum and also the Pearson coefficient quantifying the correlation between the CoF signal and the power at each frequency of the AE spectrum, both averaged over the test duration (note: a Person coefficient of 1 would indicate that both the $\mathrm{AE}$ frequency component and the $\mathrm{CoF}$ varied in an identical fashion during the test, whereas a value of zero would indicate that the two signals were completely unrelated). Fig. 5 displays a dramatic variation in Pearson coefficient with frequency indicating that some $\mathrm{AE}$ frequencies vary in a similar fashion to the CoF signal (Pearson Coefficient values close to 1), while others do not. The peaks with the maximum Pearson coefficient usually appear around 605, 675, 725, $885 \mathrm{kHz}$. More generally; at every load, the Pearson coefficients for frequency components in the ranges $100-400 \mathrm{kHz}, 540-770 \mathrm{kHz}$ and $850-1000 \mathrm{kHz}$ are relatively high while the Pearson coefficients for $400-540 \mathrm{kHz}$ and $770-850 \mathrm{kHz}$ are low and unstable. As the load increases, Pearson coefficients gradually decrease along with the frequency range with highest Pearson coefficient, except for the case of $6 \mathrm{~N}$ applied load.

The characteristic peaks, which have relatively high Pearson coefficient and high power intensity are usually around 60, 100, 150, 320, 590, 605, 675, 725 and $885 \mathrm{kHz}$. Frequencies 
components below $60 \mathrm{~Hz}$ generally have high intensity but are only weakly correlated with the friction signal. This might suggest that emission at these frequencies arises due to a source of background noise, however, this does not appear to be the case for two reasons. Firstly, this peak was not present in the recorded AE signal under zero load conditions, and secondly, as shown in Section 3.3, frequencies in this region are shown to correlate well with the measured wear.

It should be noted that $\mathrm{AE}$ signals were also recorded and analyzed during tests in which the ball specimen was oscillated but zero load was applied and no contact was made between the specimens. In this case, the intensity of the recorded $\mathrm{AE}$ frequencies were at least an order of magnitude lower than those obtained when the contact was loaded, except the individual predominant narrow noise peaks around 420, 815 and $845 \mathrm{kHz}$ which could still be distinguished (Fig. 5), especially at low loads. These noise frequency peaks had very low Pearson coefficients and had ignorable effect on the AE energy and RMS due to the very low intensities. Thus, they does not affect the AE signal analysis for the present dry friction and wear processes.
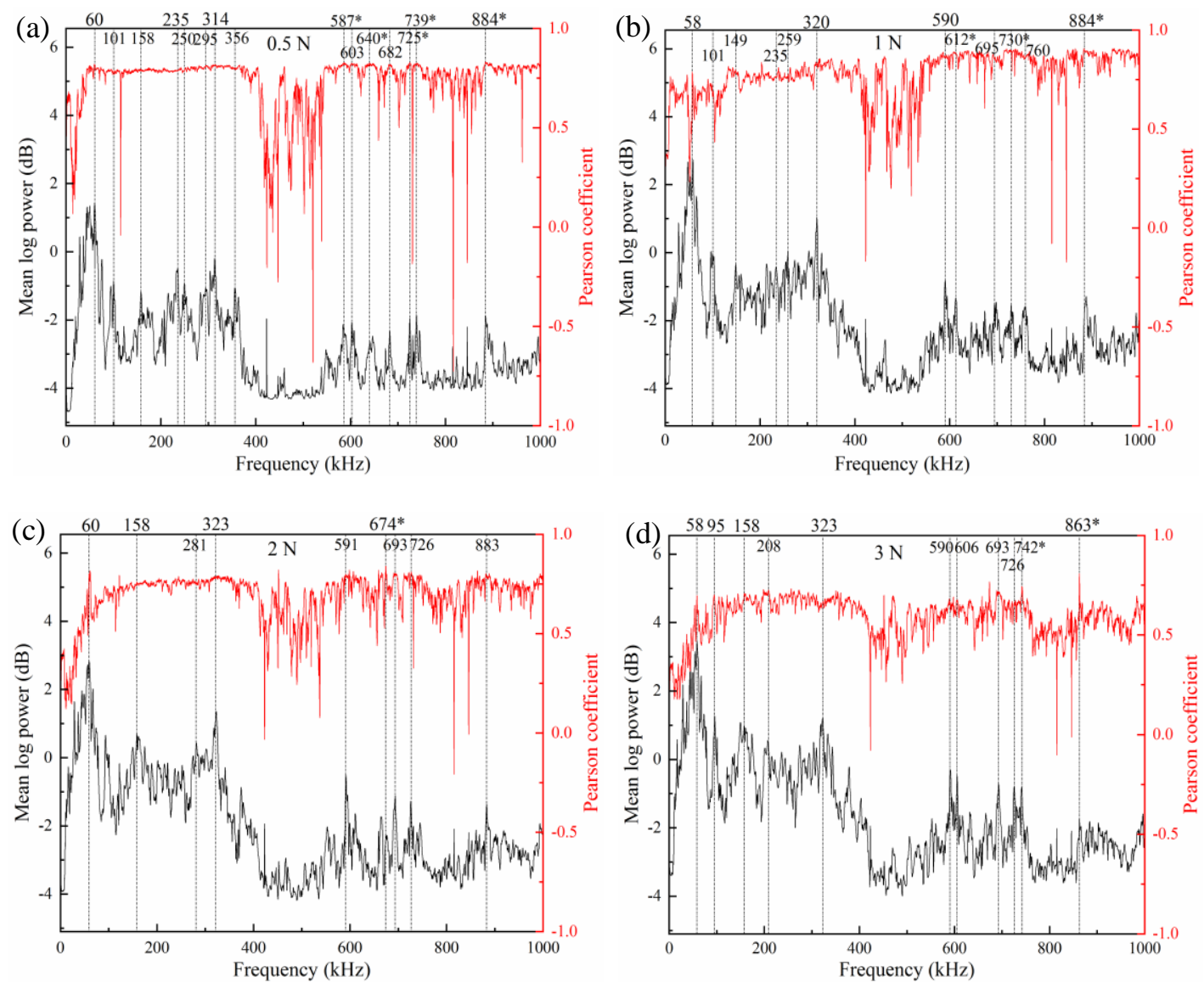

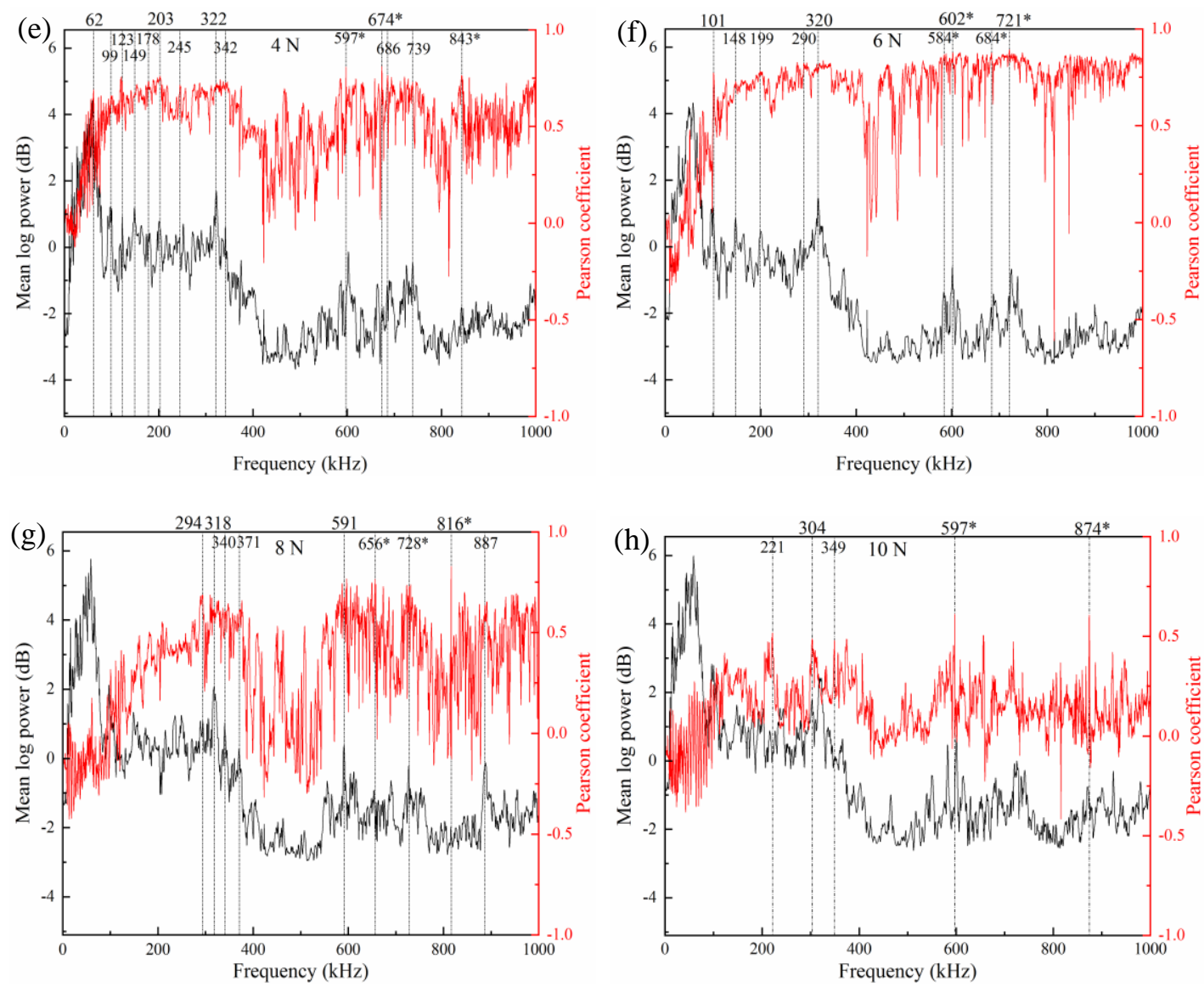

Fig. 5. Frequency spectra of $\mathrm{AE}$ and Pearson coefficient quantifying the correlation between the variation of $\mathrm{CoF}$ and $\mathrm{AE}$ power as a function of frequency: (a) $0.5 \mathrm{~N}$, (b) $1 \mathrm{~N}$, (c) $2 \mathrm{~N}$, (d) $3 \mathrm{~N}$, (e) 4 $\mathrm{N}$, (f) $6 \mathrm{~N}$, (g) $8 \mathrm{~N}$, (h) $10 \mathrm{~N}$. *Indicates the representative frequency for which the Pearson coefficient is (or is close to) a maximum value.

The variations in $\mathrm{CoF}$ and $\mathrm{AE}$ parameters with time under different loads are shown in Fig. 6 (a-f), while the person coefficient associated with each of these plots are summarized in Fig 6(g). The frequency component with the maximum Pearson coefficient (i.e. the frequency whose power best reflects the CoF signal - denoted "MaxP frequency") shows a trend which is very similar to the CoF (Fig. 6a). The Pearson coefficients of these frequencies maintain values are at least as high as 0.8 under 0.5-8 N. However, under $10 \mathrm{~N}$, the maximum Pearson coefficient is only 0.61.

Under $0.5 \mathrm{~N}$, the maximum power of the AE signal (peak frequency), the RMS and the AE energy show a good correlation with the CoF (Fig. 6b-d). As the load increases, their correlations with the CoF decrease (Fig. 6g). However, they have a good correlation with each other over the whole range of loads, which indicates that the RMS is related to the AE energy and they are both dominated by the power of the peak frequency. This is important because it means that information carried by the AE signals at frequencies outside the maximum power region will be lost if only RMS or AE energy is monitored (as is commonly the case).

The variation of the MNF with time does not correlate well with the CoF (Fig. 6e) and the Pearson coefficient is low (Fig. 6g). The variation of MDF with time correlates well with the CoF under $0.5 \mathrm{~N}$ (Fig. 6f), but as the load increases, their correlation becomes low (Fig. 6g).

The Pearson coefficient values shown in Fig. $6 \mathrm{~g}$ have been obtained by correlating friction and 
$\mathrm{AE}$ signals over each $600 \mathrm{~s}$ duration test. At the beginning of the tribological process, especially under 4-10 N, AE signals and $\mathrm{CoF}$ are poorly correlated, which reduces the overall Pearson coefficient for the test as a whole. Taking the MNF and MDF as examples (Fig. 6e and f); if the initial stage of several seconds is removed, their Pearson coefficients can be increased (Fig. 7a and b). This suggests different mechanisms of $\mathrm{AE}$ generation occurring during running in compared to prolonged sliding - a feature which will be investigated in future studies.

(a) $\mathrm{CoF} \&$ most highly correlated $\mathrm{AE}$ frequency (b) $\mathrm{CoF} \& \mathrm{AE}$ freq with highest intensity

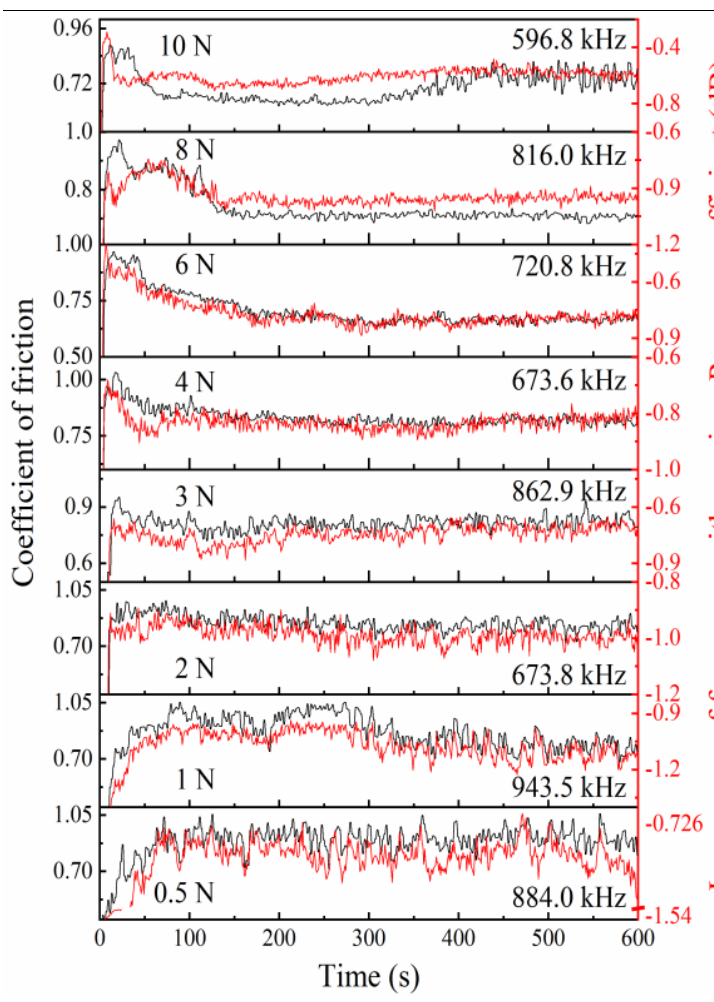

(c) CoF \& RMS of AE signal

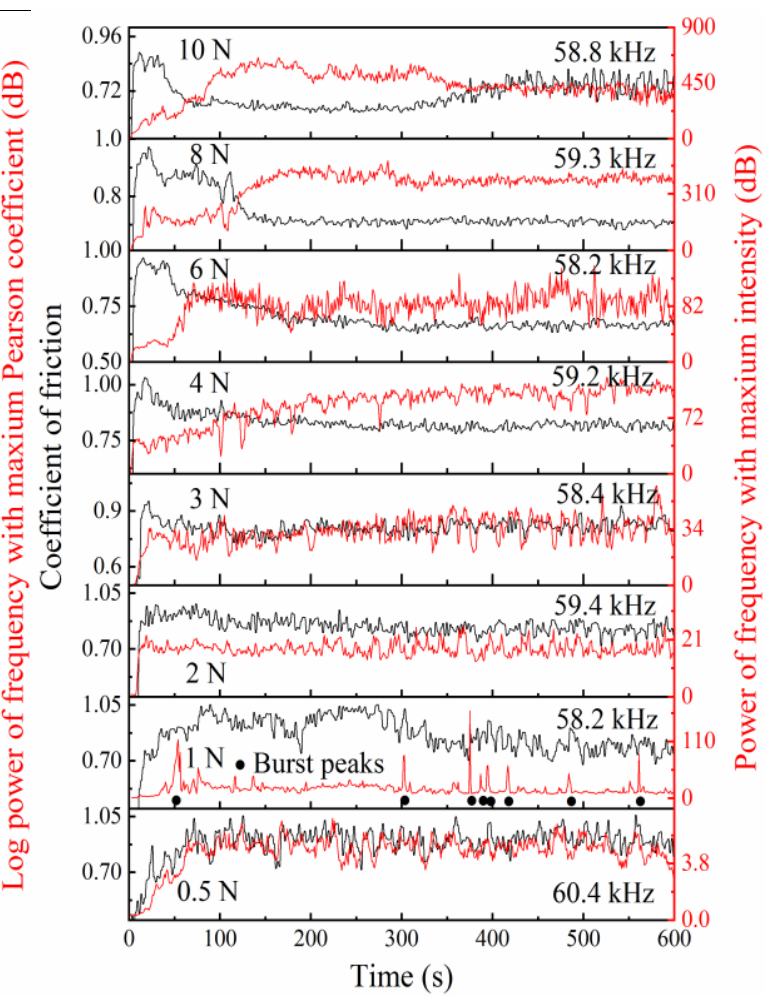

(d) CoF \& AE signal energy 


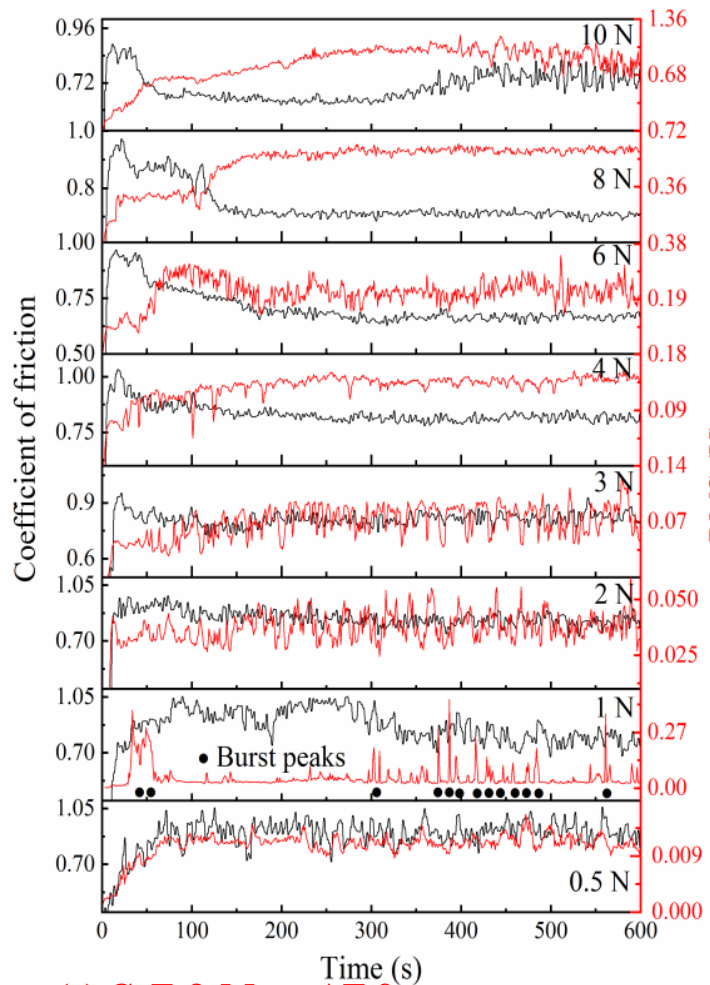

(e) $\mathrm{CoF} \&$ Mean $\mathrm{AE}$ frequency

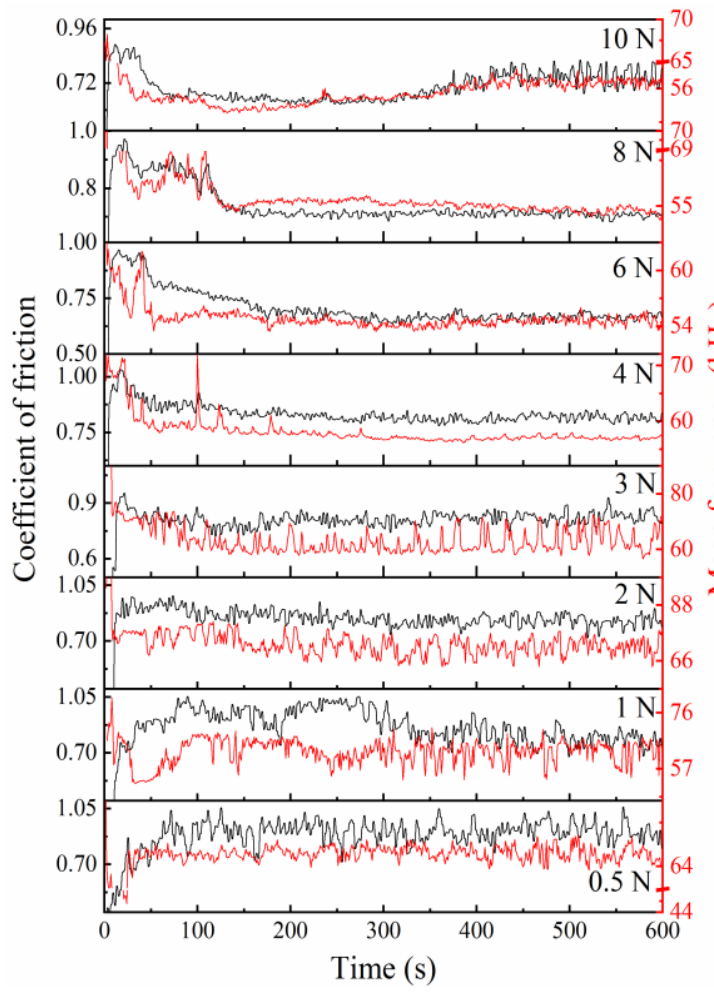

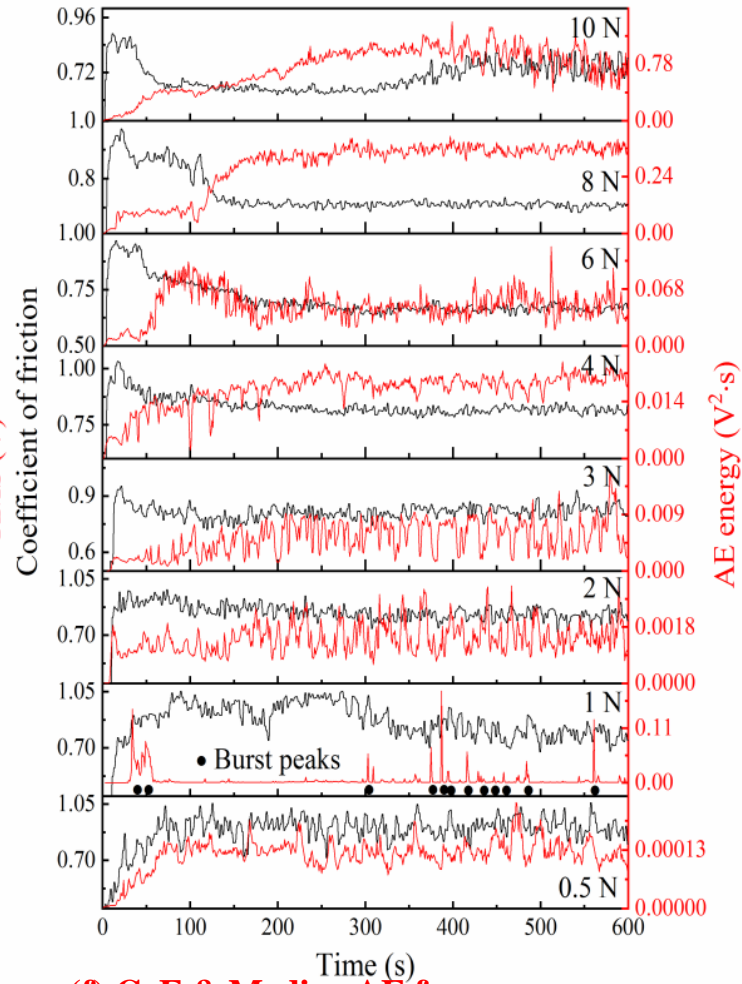

(f) $\mathrm{CoF} \& \mathrm{Median} \mathrm{AE}$ frequency

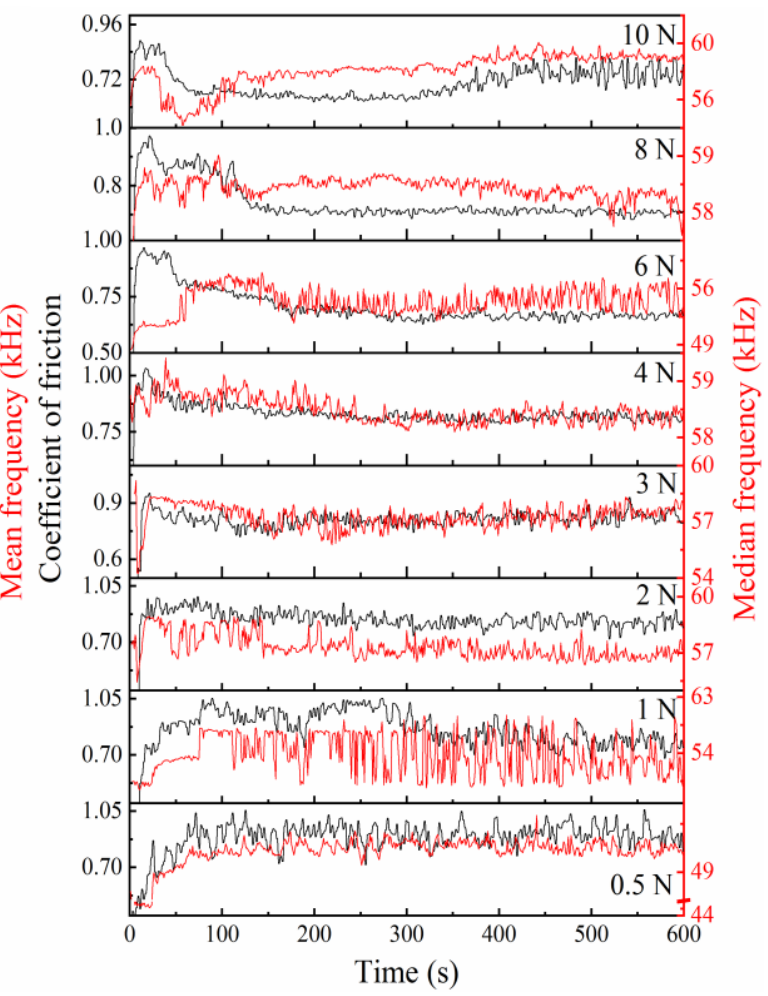




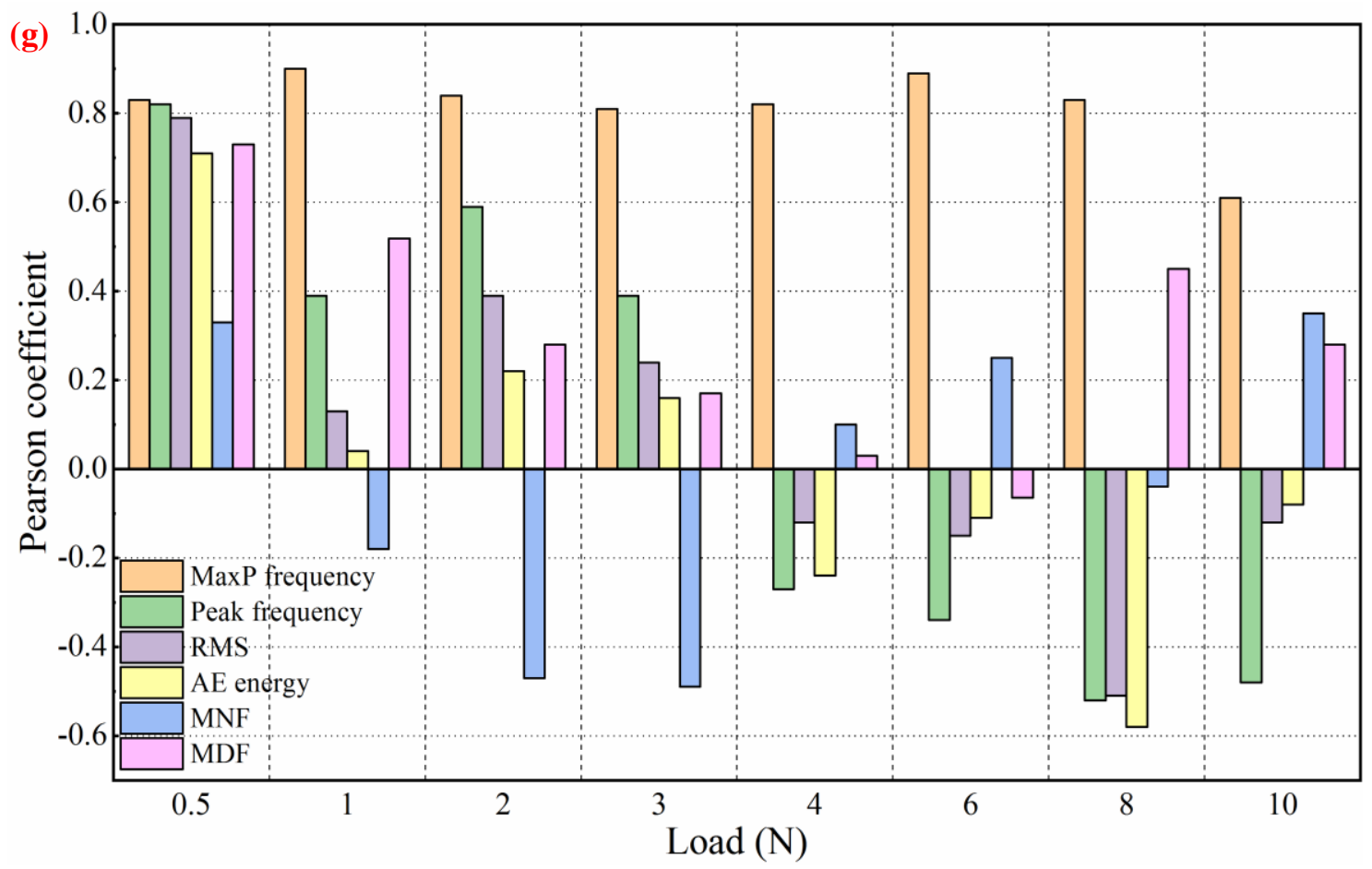

Fig. 6. Comparison between the variation of the $\mathrm{CoF}$ and different $\mathrm{AE}$ parameters with time under 0.5-10 N: (a) CoF \& log power of frequency with maximum Pearson coefficient, (b) CoF \& power of the frequency with maximum intensity, (c) CoF \& RMS, (d) CoF \& AE energy, (e) CoF \& MNF, (f) $\mathrm{CoF} \& \mathrm{MDF}$, (g) Summary of Pearson coefficients quantifying the correlation between the CoF signal and each of varying $\mathrm{AE}$ signal parameters in plots (a)-(f).
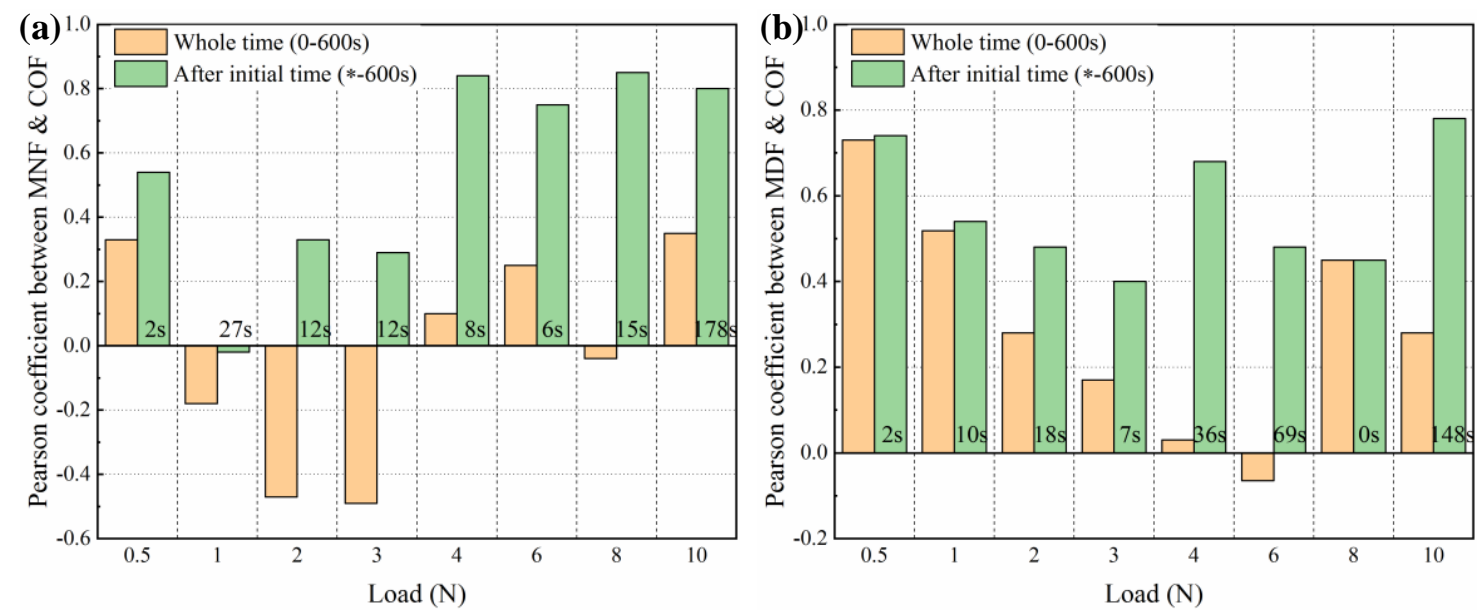

Fig. 7 Pearson coefficients quantifying the correlation between the variation curves of the AE signals and CoF for the whole test duration and for part of the test: (a) MNF \& CoF and (b) MDF \& CoF.

Several recent studies $[1,26,27]$ emphasize the importance of calculating the mean and median frequencies of the $\mathrm{AE}$ signal and correlating these with friction and wear measurements. To study this ourselves, the relationships between the $\mathrm{AE}$ characteristic parameters and the friction averaged over each test are plotted in Fig. 8 (note: here, the frictional work is found by integrating the friction force over the sliding distance). The mean frequency of the AE signal increases approximately 
linearly with the CoF, whereas the median frequency of the AE signal increases rapidly with the frictional work under 0.5-3 $\mathrm{N}$ loads and then increases more slowly at higher loads. Fig. 8 also shows that both the average RMS and AE energy increase in a pronounced linear fashion with the frictional work. They increase slowly under $0.5-6 \mathrm{~N}$ load, and then more rapidly under 6-10 N, indicating a change in mechanism at around $6 \mathrm{~N}$, which is investigated using surface analysis in Section 3.4.
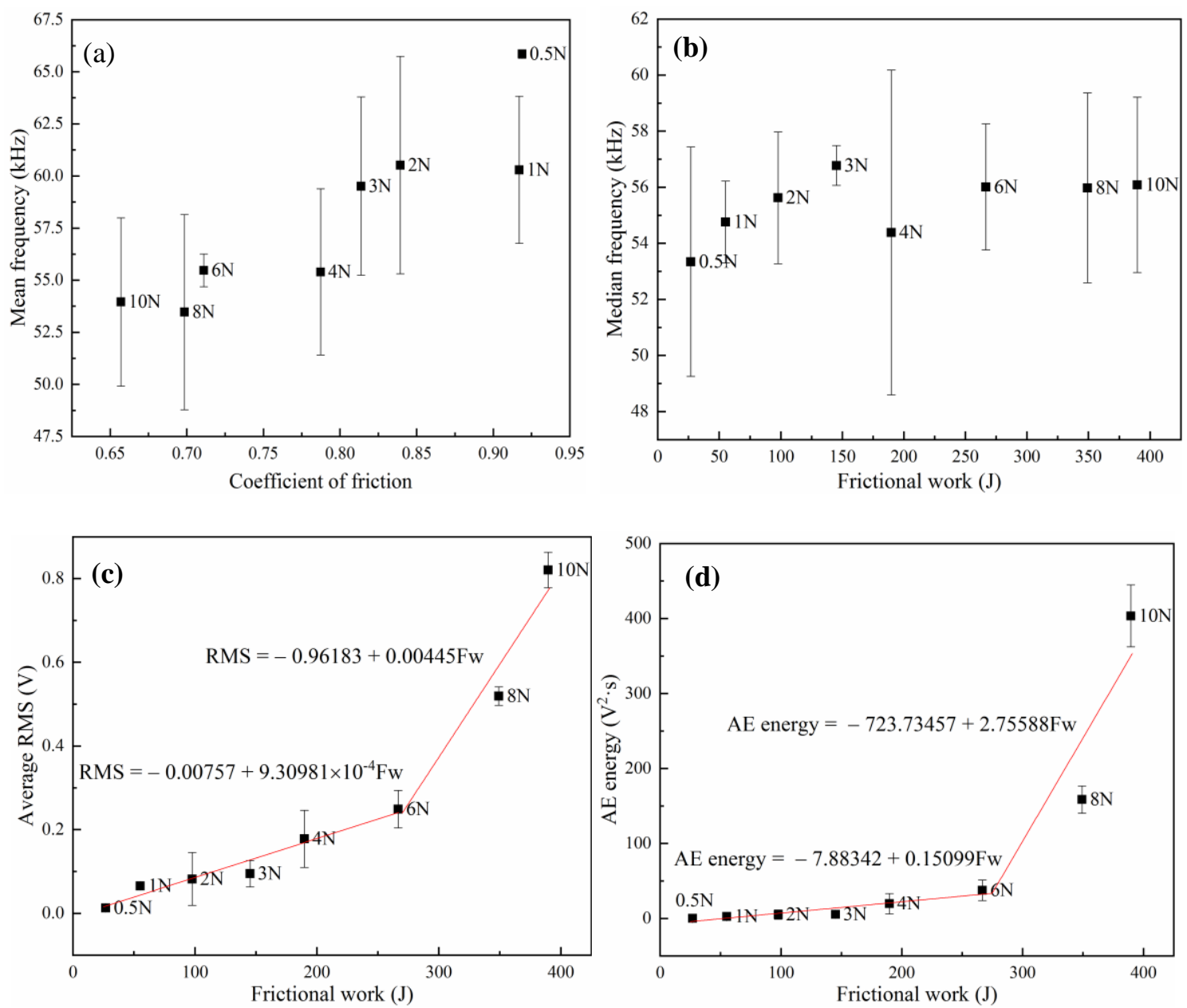

Fig. 8 Correlations of integrated AE parameters with integrated friction: (a) mean frequency and coefficient of friction, (b) median frequency and frictional work, (c) average RMS and frictional work $(\mathrm{Fw}),(\mathrm{d}) \mathrm{AE}$ energy and frictional work $(\mathrm{Fw})$

\subsection{Acoustic emission and wear}

The relationships between the AE signals and wear volumes are shown in Fig. 9. Both the average RMS and the AE energy have a piecewise linear relation with the wear volume. Under $0.5-6 \mathrm{~N}$ load, they increase linearly with the wear volume. However, as the load increases to 8 and $10 \mathrm{~N}$, they increase more rapidly (note that, as with friction plots in Fig 8, the change in slope occurs at $6 \mathrm{~N}$ ). The median frequency increases with the wear volume below $2 \mathrm{~N}$ and then becomes approximately stable as the load increases.

It is of interest to assess the relationship between the wear volume and individual frequency components of the $\mathrm{AE}$ signal. To do this, the average $\mathrm{AE}$ frequency spectrum from each test is plotted against load in Fig. 10. This can be considered as a plot of AE frequency vs. wear, since wear 
volume increases monotonically with load according to Fig. 3. It can be seen from Fig. 10 that the $\mathrm{AE}$ frequencies around $60 \mathrm{kHz}$ show very strong correlation with increasing load/wear volume. Inspection of Fig. 10 reveals a broadening of the frequency peaks in the AE signal as load/wear volume increase, and this accounts for the correlation between AE RMS and energy with the wear, shown in Fig 9a and $b$.
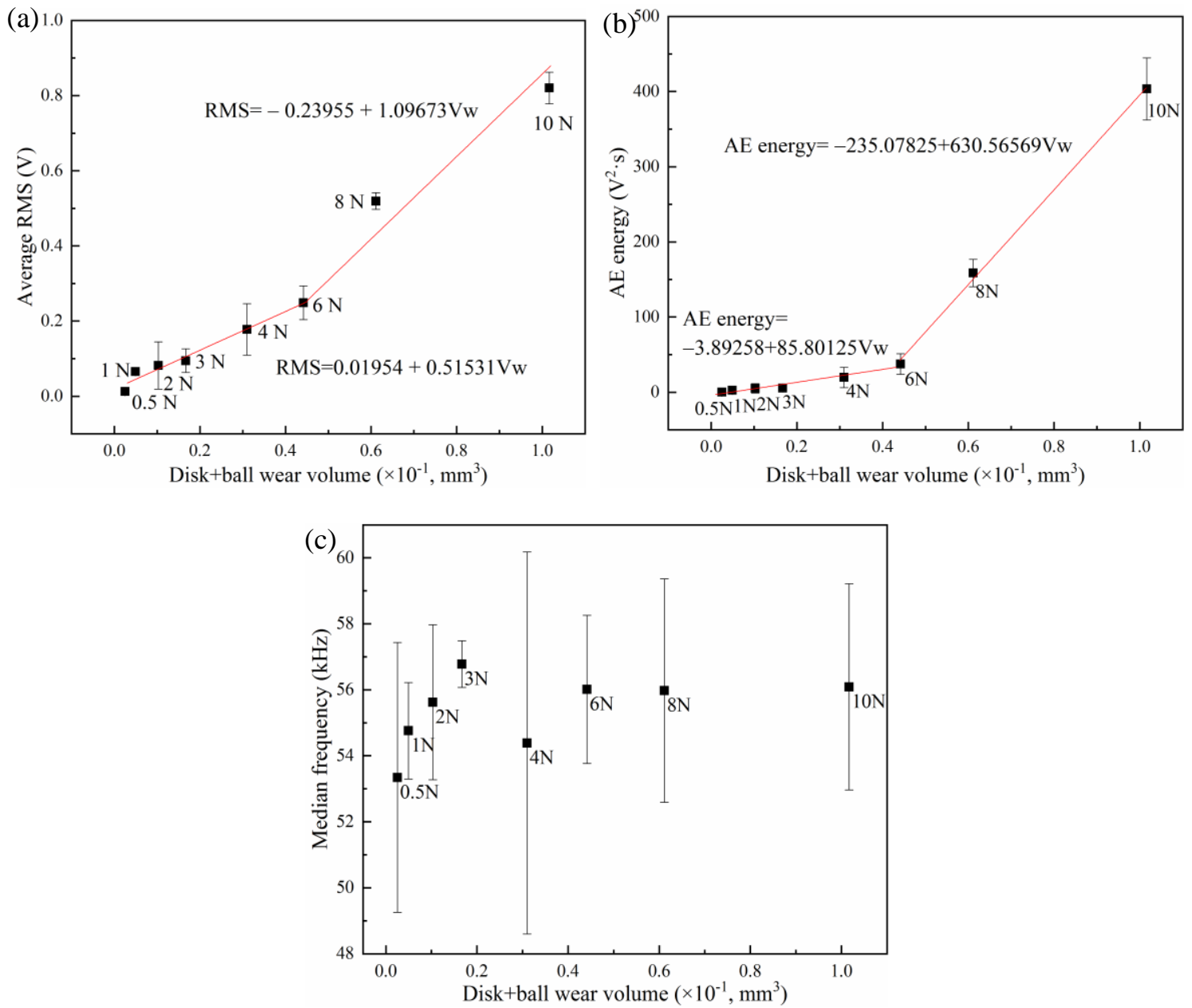

Fig. 9 Correlations between the AE parameters and wear volumes ( $\mathrm{Vw}$ ): (a) average RMS and wear volume, (b) AE energy and wear volume, (c) median frequency and wear volume.

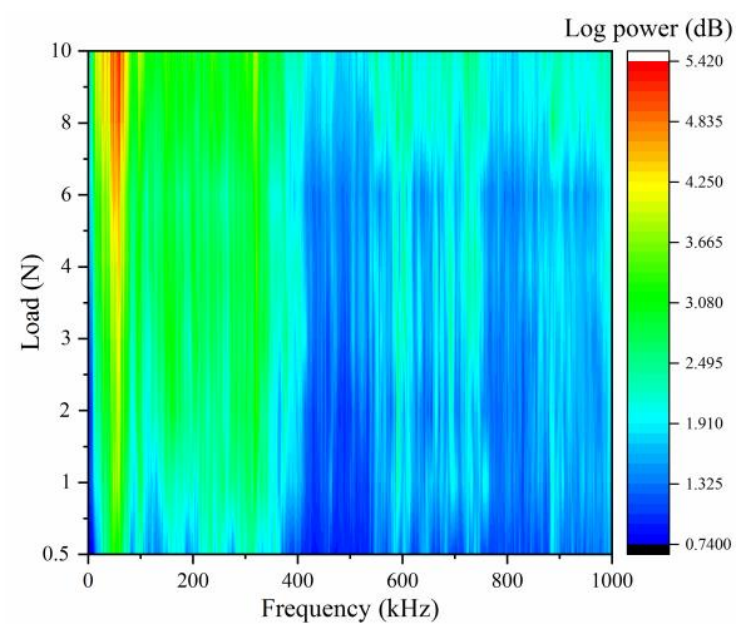

Fig. 10 Variation of the intensity of each frequency with load (the latter being a proxy for wear 
volume according to Fig. 3).

\subsection{Morphology and phases of worn surfaces}

The worn surface morphologies of the steel ball and disc are shown in Fig. 11. After the tribotest under $0.5 \mathrm{~N}$, shallow and regular linear grooves were seen on the worn surface of both the ball and disc (Fig. 11a and b). These appear to be due to debris particles (whose presence increases the pressure above the yield stress) embedded into the disc, since several of the disc grooves terminate in a debris particle while no particles were present on the ball. On the surface of the disc, the dark areas were iron oxides as confirmed by EDX, and these areas appear to be intact. Under $1 \mathrm{~N}$, the oxide areas on the disc are smaller and appear to be broken into debris leaving pits on the disc (Fig. 11d). This is accompanied by the presence of debris on the ball surface at the contact inlet (Fig. 11c). When the load was increased to $2 \mathrm{~N}$, the wear scar on the ball increased in size but the features remained unchanged (Fig. 11e) while on the disc surface, discontinuous oxide debris gathered to become blocky layers (Fig. 11f). Under 3 and 4 N, oxide layers emerged in the middle of the worn surface of the ball (Fig. 11g and i). Wide and deep furrows, plastic deformation and pits were then seen on the disc surface and the area between the furrows became relatively smooth and oxide free (Fig. 11h and j). Under $6 \mathrm{~N}$, the oxide debris combined to form large flakes on the worn surface of the ball (Fig. 11k). This was accompanied by the central area of the disc scar becoming smooth while accumulating oxide debris at the edges (Fig. 111). As the load increased to 8-10 N, regions of oxide debris were present on both the worn surface of the ball (Fig. $11 \mathrm{~m}$ and o), and the disc (Fig. 11n), and these became rougher. Additional pits, material fracture traces and oxide wear debris appeared under $10 \mathrm{~N}$ (Fig. 11p). It can be generally concluded from Fig. 11 that at the lowest loads, oxide forms predominantly on the disc surface and wear is caused by plastic deformation of the steel. At higher loads, oxide adheres to the ball surface, which abrades the disc. Then at the highest loads, oxide regions are present of both surfaces.
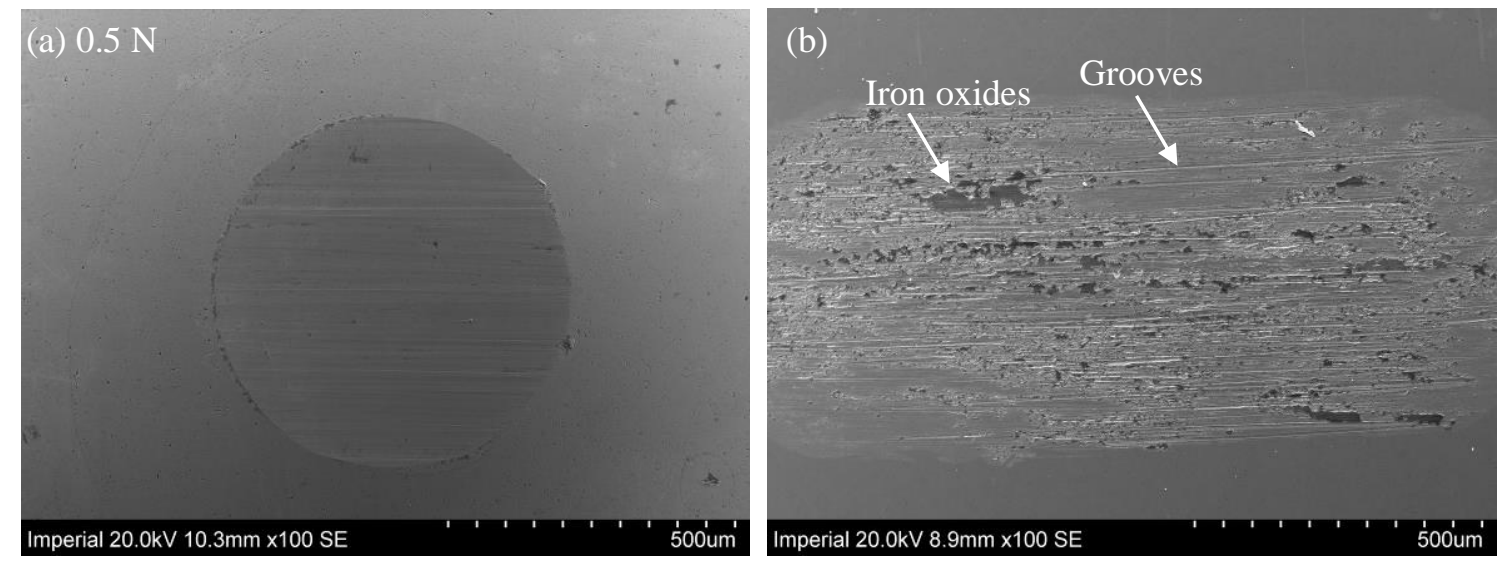

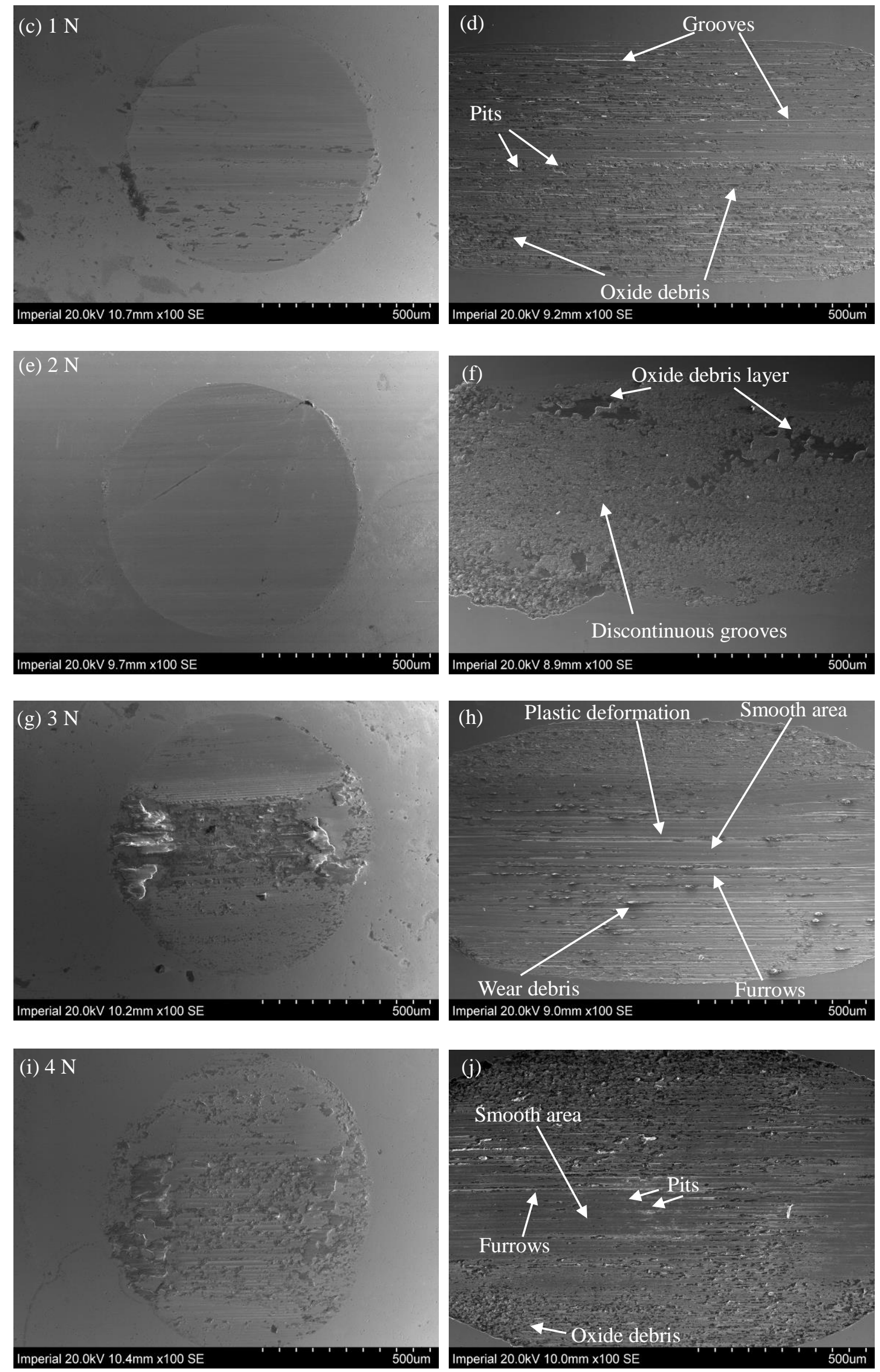

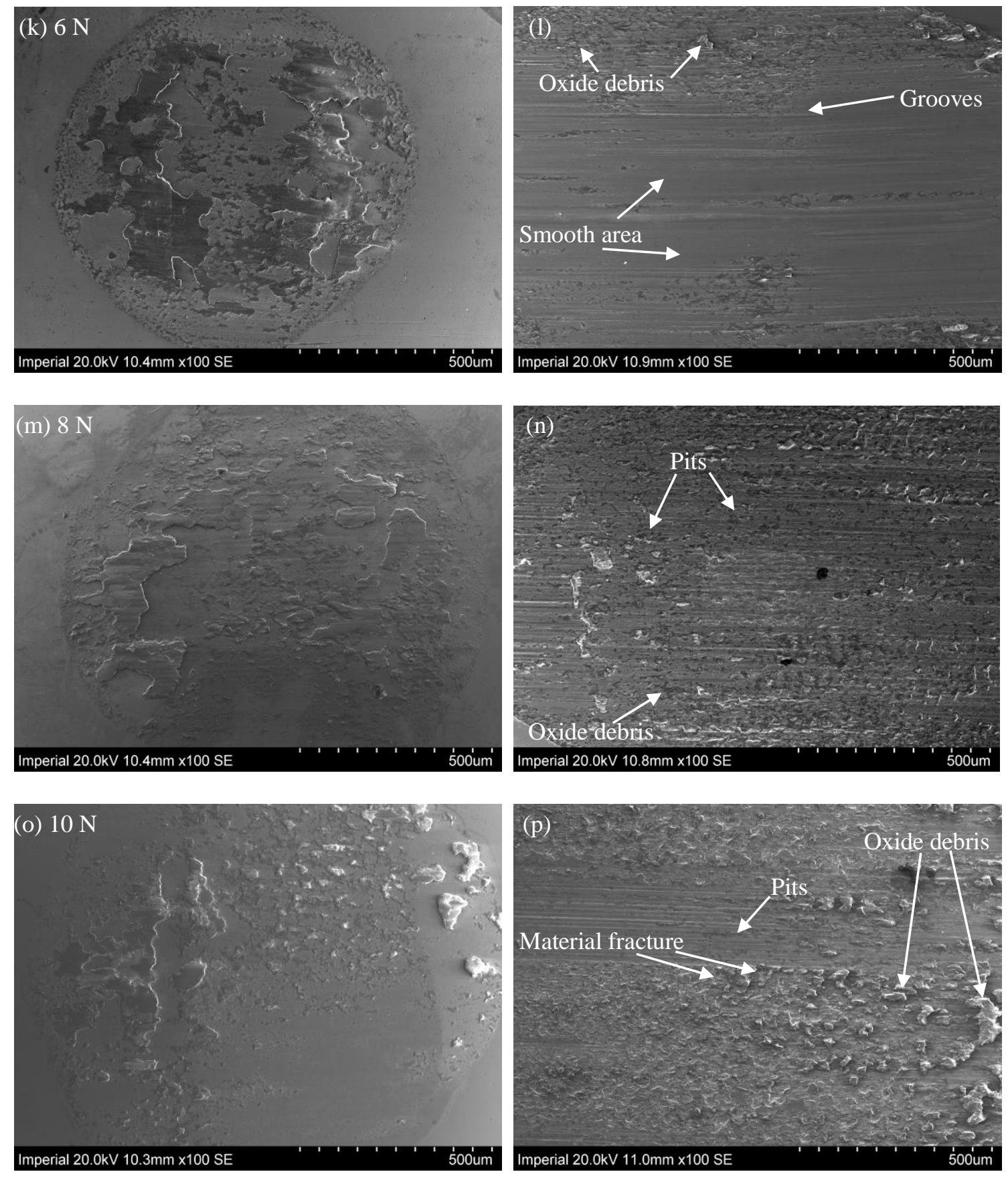

Fig. 11 Surface morphology of the worn track on the balls and discs after the tribotests under different normal loads: (a) ball- $0.5 \mathrm{~N}$, (b) disc- $0.5 \mathrm{~N}$ (c) ball-1 N, (d) disc-1 N, (e) ball-2 N, (f) disc-2 N, (g) ball-3 N, (h) disc-3 N, (i) ball-4 N, (j) disk-4 N (k) ball-6 N, (l) disc-6 N, (m) ball-8N, (n) disc- $8 \mathrm{~N}$, (o) ball-10 N, (p) disc-10 N.

Raman spectra of the adhered material on the worn surface of the ball and disc are shown in Fig. 12. After the tribotest under $0.5 \mathrm{~N}$, the oxides on the worn surface of the ball and disc were mainly $\gamma-\mathrm{Fe}_{2} \mathrm{O}_{3}$. As the load increased, $\mathrm{Fe}_{3} \mathrm{O}_{4}$ and $\alpha-\mathrm{Fe}_{2} \mathrm{O}_{3}$ became the dominant oxides on the worn surface. Under $0.5-6 \mathrm{~N}$, the peak intensities of the oxides on the disc's worn surface are stronger than those on the ball worn surface. Under 8-10 N, the peak intensities of the oxides on the ball worn surface increase significantly and are stronger than those on the disc worn surface, which indicates that 
many oxides adhered on worn surface of the ball and the oxides experienced plowing and could be removed from the worn surface of the disc.
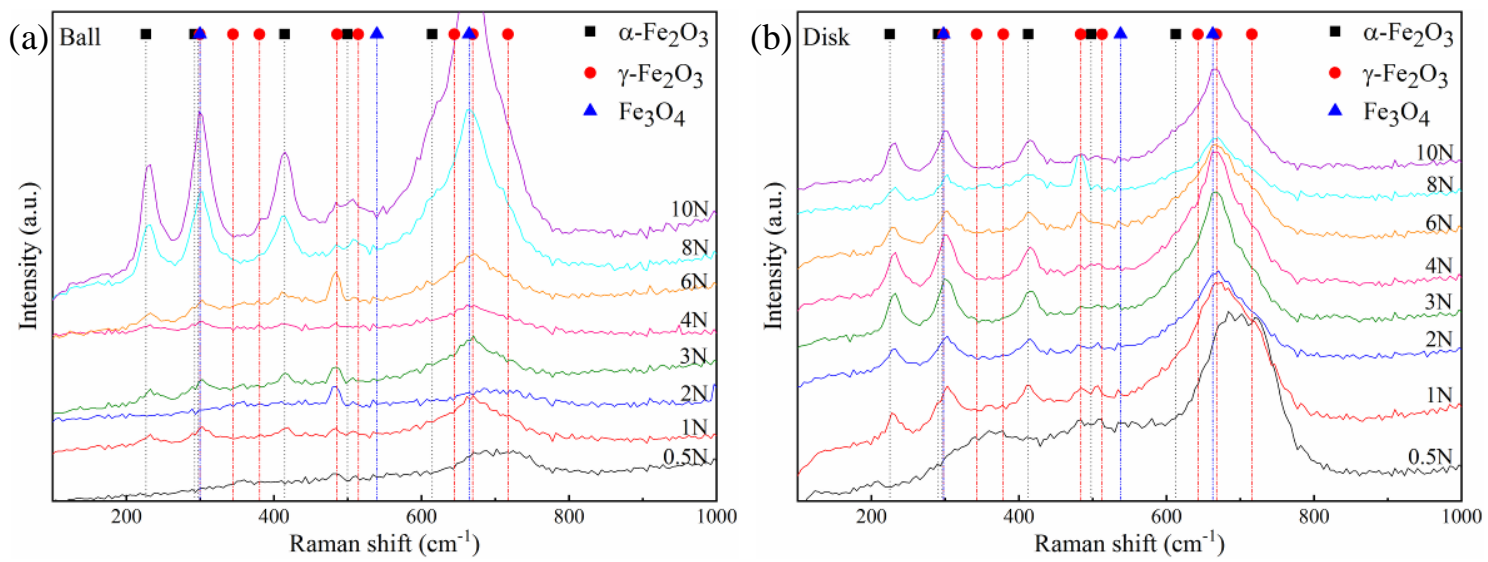

Fig. 12 Raman spectra of the adhered material on the worn surfaces after tribotest: (a) ball; (b) disk.

\section{Discussion}

These results for a dry sliding steel-steel contact demonstrate that AE signals, if processed correctly, closely reflect tribological behavior. More specifically, certain features extracted from AE waveform in frequency domain correlate well with friction while others correlate with wear. Individual frequency components give high Pearson coefficients for their correlation with the CoF (Fig. 6a) and hence contain information of asperity interaction. In fact, these components are often considerably better correlated with $\mathrm{CoF}$ than are other commonly used signal parameters such as the mean frequency, the median frequency, RMS or the AE energy.

When considering wear volume, it is the frequency components with the highest intensity (around 60 $\mathrm{kHz}$ ) that correlate best (Fig. 10). During the initial stages of each of the tests under $4-10 \mathrm{~N}$ (Fig. $6 \mathrm{~b}$ ), the $\mathrm{CoF}$ is high while the power of the frequency with high intensity is low and increasing. This corresponds to running in and provides further evidence that the frequencies with high intensities relate to wear. The frequencies with high intensities largely determine the AE signal's RMS value and energy, which explains why the RMS and AE energy have a close relationship with wear. This also suggests that these two widely used $\mathrm{AE}$ parameters are less sensitive to friction since the relevant frequency components are drowned out by the wear sensitive, high intensity components.

Fig. 13 summarizes the relationships between the AE signal parameters and tribological behaviour and can be understood by examining the SEM images in Fig. 11, as follows. Under 0.5 N, the maximum hertz pressure $(0.506 \mathrm{GPa})$ is lower than the material yield stress, however yielding occurs locally due to debris to cause mild plastic abrasive wear. This induces friction and wear and simultaneously produces acoustic emission, probably due to increased dislocation densities caused by plastic deformation as suggested by James et al. [40] and Kiesewetter et al. [41]. Some oxide is produced, but remains in place on the disc surface. As a result, the variation with time of the $\mathrm{AE}$ signal characteristics such as the power of most frequencies components, RMS, AE energy and MDF all showed good correlation with the CoF signal (Fig. 6). Moreover, under low loads, the minimal wear and hence constant contact geometry during each test is also likely to improve the correlations with $\mathrm{AE}$ signals. Under $1 \mathrm{~N}$, the reciprocating motion of the asperities causes the fatigue of surface material in the locally in grooves and the fracture and detachment of oxide layers to leave pits (Fig. 
11d). This oxide fracture likely to cause the burst peaks observed in the RMS, AE energy and at certain frequencies (see burst peaks in Fig. 6b, c and d). It is evident from Fig. 6 that these burst peaks are not detected by the CoF as strongly as they are in the AE RMS, energy and at certain AE frequencies. Thus, the RMS did not correlate well with the CoF (Fig. 6c) - a discrepancy that is due to the $\mathrm{AE}$ signal containing more tribological information than the $\mathrm{CoF}$ [32].

At all times during tests under a load of $3 \mathrm{~N}$ or less, oxide is present on either surface of the contact but not both. The predominant wear mechanism is therefore abrasive wear and involves plastic deformation. Here, the friction and wear volume are proportional to the AE signals energy and RMS, which increase with load due to the increasing real area of contact.

As the load increased from 3 to $6 \mathrm{~N}$, the amount of oxide debris starts to increase substantially, particularly on the surface of the ball. These layers become crushed and are moved along the interface. Despite the increased amounts of oxide under these intermediate loads, it is again apparent that oxide is generally only present on one of the two contacting surfaces (it is either attached to the ball or the disc). As a result, the wear mechanism still involves predominantly plastic deformation of the steel.

At $6 \mathrm{~N}$ and above, the oxide debris adheres to both the ball and the disc surfaces preventing direct contact between asperities on the opposing components (Fig. 10n and p) - i.e. oxidative wear ensues and the local contact between the specimens occurs at oxide-oxide junctions rather than steel-steel or oxide-steel. This increased oxide-oxide contact and fracture has a greater effect on the acoustic emission signal than is does on the wear and friction signals, which explains the discontinuity and increased gradient in the wear vs. RMS and energy plots shown in Fig. 9a and b. It also explains the poorer correlation between $\mathrm{AE}$ frequencies and $\mathrm{CoF}$ under $10 \mathrm{~N}$ load, since friction inducing plastic deformation is reduced while noisy oxide fracture is increased. However, the mean frequency remained well correlated with $\mathrm{CoF}$.

These observations are in agreement with several studies on thermal cycling, which have shown that high levels of acoustic emission result from the fracture of oxide surface layers (e.g. Khanna et al. [42], Christl et al. [43] and Shankar et al. [44]).

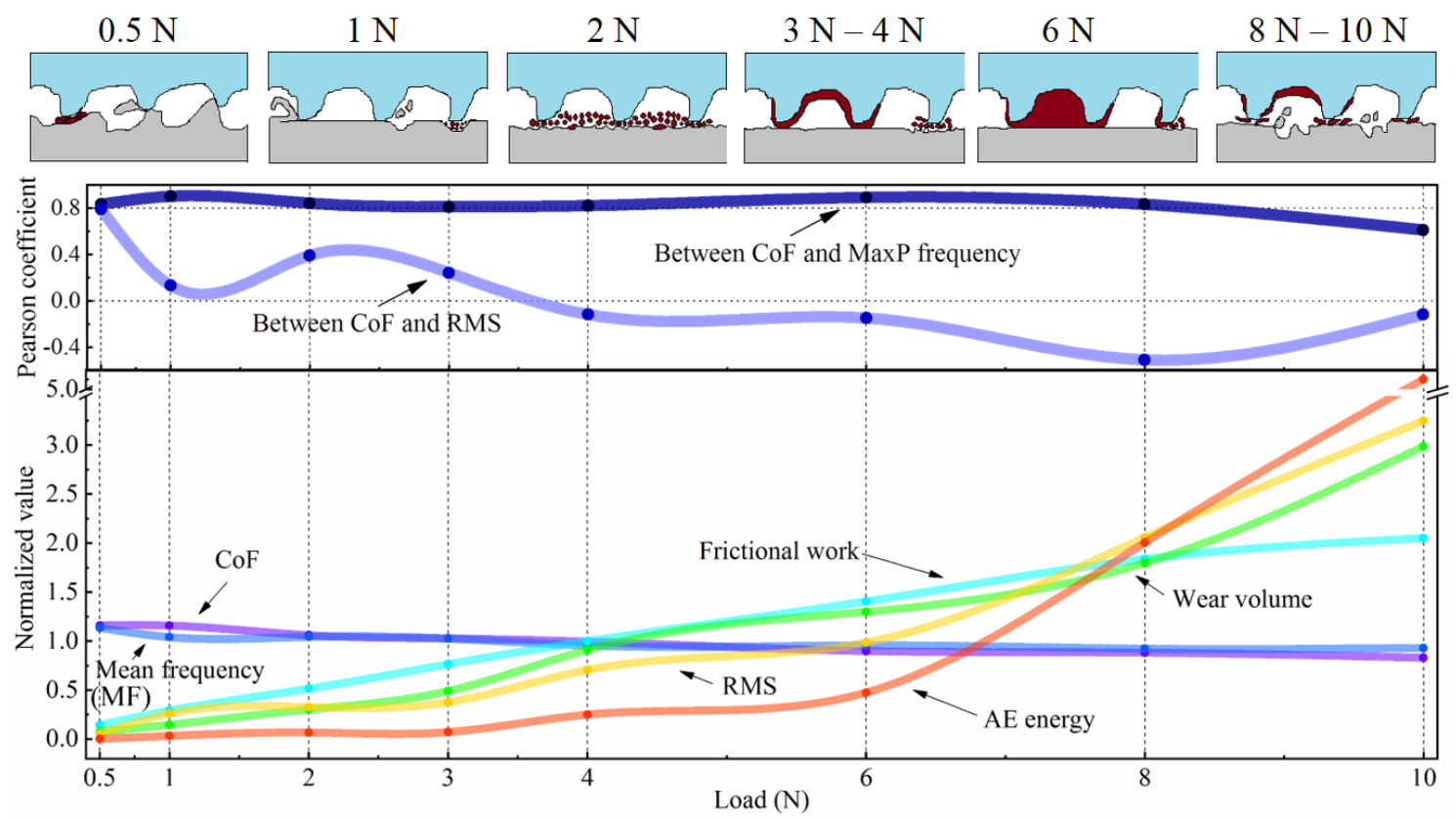

Fig.13 Relationship between AE parameters, tribological parameters and wear mechanisms 
(normalized values from Figs 3 and 6 vs. time).

\section{Conclusions}

For the dry reciprocating tribological tests of 52100 steel balls and discs under $0.5-10 \mathrm{~N}$, the correlations between the $\mathrm{AE}$ signals and tribological behavior were studied, and the following conclusions were obtained

Different frequency characteristics of the AE signal correlate well with the friction and wear in different ways. For instance, the variation of the power of certain frequencies over time is very similar to that of the CoF, as evidenced by high Pearson coefficients. However, other frequencies (those with high intensities) are more closely related with wear. In addition to this, increasing wear appears to be related to a broadening of the frequency peaks in the AE signal. Other more commonly used AE signal parameters such as RMS, energy, MFT and MDF are comparatively poor at predicting friction behaviour. One reason for this is that the RMS and energy of the AE signal are largely determined by the frequency components with largest amplitude, which means that smaller, frequency sensitive, components are obscured. In summary, this suggests that an acoustic emission spectroscopy approach is an effective means of monitoring tribological contacts, as it allows the relevant components of the $\mathrm{AE}$ signal to be isolated.

The AE signal contains more information and is more sensitive to changing wear mechanisms than the CoF and wear volume measurements. For instance, the AE RMS and energy could detect the fracture of material and the movement of wear debris which emit the high levels acoustic sound while not significantly affecting the $\mathrm{CoF}$ or wear volume.

This all suggests that $\mathrm{AE}$ can be a powerful tool to monitor tribological behavior, particularly in machine contacts where friction and wear measurements are not possible. However, further work is required to gain a more detailed understanding of why acoustic emission generation is so frequency dependent.

\section{Acknowledgements}

The authors want to thank Dr. Ciniero, Mr. Bahshwan and Mr. Loh for their help on the AE experiments and the data processing. This work was supported by the Overseas Study Program of Jiangsu Higher Education Institutions; the Natural Science Foundation of Jiangsu Province, China (Grant no. BK20160353); the Natural Science Foundation of Jiangsu Higher Education Institutions (Grant no. 16KJB460032); the Key Laboratory of Suzhou (SZS201815); the Top-notch Academic Programs Project of Jiangsu Higher Education Institutions (TAPP) (Grant no. PPZY2015B186) and the Scientific Research Foundation of SIIT (Grant no. 2017kyqd015).

\section{References}

[1] Shanbhag VV, Rolfe BF, Arunachalam N, Pereira MP. Investigating galling wear behaviour in sheet metal stamping using acoustic emissions. Wear. 2018;414-415:31-42.

[2] Rastegaev IA, Merson DL, Danyuk AV, Afanasyev MA, Vinogradov A. Using acoustic emission signal categorization for reconstruction of wear development timeline in tribosystems: Case studies and application examples. Wear. 2018;410-411:83-92.

[3] Elasha F, Greaves M, Mba D, Fang D. A comparative study of the effectiveness of vibration and acoustic emission in diagnosing a defective bearing in a planetry gearbox. Applied Acoustics. 
2017;115:181-95.

[4] Filippov AV, Rubtsov VE, Tarasov SY. Acoustic emission study of surface deterioration in tribocontacting. Applied Acoustics. 2017;117:106-12.

[5] Matsuoka K, Taniguchi K, Nakakita H. In-situ wear monitoring of slider and disk using acoustic emission. Journal of Tribology-Transactions of the Asme. 2001;123:175-80.

[6] Strombergsson D, Marklund P, Edin E, Zeman F. Acoustic emission monitoring of a mechanochemical surface finishing process. Tribology International. 2017;112:129-36.

[7] Boaron A, Weingaertner WL. Dynamic in-process characterization method based on acoustic emission for topographic assessment of conventional grinding wheels. Wear. 2018;406:218-29.

[8] Sadegh H, Mehdi AN, Mehdi A. Classification of acoustic emission signals generated from journal bearing at different lubrication conditions based on wavelet analysis in combination with artificial neural network and genetic algorithm. Tribology International. 2016;95:426-34.

[9] Toutountzakis T, Tan CK, Mba D. Application of acoustic emission to seeded gear fault detection. Ndt \& E International. 2005;38:27-36.

[10] Dobrynin SA, Kolubaev EA, Smolin AY, Dmitriev AI, Psakhie SG. Time-frequency analysis of acoustic signals in the audio-frequency range generated during Hadfield's steel friction. Technical Physics Letters. 2010;36:606-9.

[11] Hisakado T, Warashina T. Relationship between friction and wear properties and acoustic emission characteristics: iron pin on hardened bearing steel disk. Wear. 1998;216:1-7.

[12] Sarychev GA, Shchavelin VM. Acoustic emission method for research and control of friction pairs. Tribology International. 1991;24:11-6.

[13] Hase A, Wada M, Mishina H. The relationship between acoustic emissions and wear particles for repeated dry rubbing. Wear. 2008;265:831-9.

[14] Hase A, Mishina H, Wada M. Microscopic study on the relationship between AE signal and wear amount. Wear. 2013;308:142-7.

[15] Ferrer C, Salas F, Pascual M, Orozco J. Discrete acoustic emission waves during stick-slip friction between steel samples. Tribology International. 2010;43:1-6.

[16] Meriaux J, Boinet M, Fouvry S, Lenain JC. Identification of fretting fatigue crack propagation mechanisms using acoustic emission. Tribology International. 2010;43:2166-74.

[17] Sun J, Wood RJK, Wang L, Care I, Powrie HEG. Wear monitoring of bearing steel using electrostatic and acoustic emission techniques. Wear. 2005;259:1482-9.

[18] Benabdallah HS, Aguilar DA. Acoustic Emission and its Relationship with Friction and Wear for Sliding Contact. Tribology Transactions. 2008;51:738-47.

[19] Wang L, Wood RJK. Acoustic emissions from lubricated hybrid contacts. Tribology International. 2009;42:1629-37.

[20] Jiaa CL, Dornfeld DA. Experimental studies of sliding friction and wear via acoustic emission signal analysis. Wear. 1990;139:403-24.

[21] Benabdallah HS, Boness RJ. Tribological behaviour and acoustic emissions of alumina, silicon nitride and SAE52100 under dry sliding. Journal of Materials Science. 1999;34:4995-5004.

[22] Boness RJ, McBride SL, Sobczyk M. Wear studies using acoustic emission techniques. Tribology International. 1990;23:291-5.

[23] Boness RJ, Hawthorne HM. Acoustic emission from the unlubricated sliding wear of steel and silicon nitride. Tribology Transactions. 1995;38:293-8.

[24] Hase A, Wada M, Mishina H. Acoustic Emission Signals and Wear Phenomena on Severe-Mild Wear 
Transition. Tribology Online. 2008;3:298-303.

[25] Kolubaev EA, Kolubaev AV, Sizova OV. Analysis of acoustic emission during sliding friction of manganese steel. Technical Physics Letters. 2010;36:762-5.

[26] Lychagin DV, Filippov AV, Kolubaev EA, Novitskaia OS, Chumlyakov YI, Kolubaev AV. Dry sliding of Hadfield steel single crystal oriented to deformation by slip and twinning: Deformation, wear, and acoustic emission characterization. Tribology International. 2018;119:1-18.

[27] Filippov AV, Tarasov SY, Fortuna SV, Podgornykh OA, Shamarin NN, Rubtsov VE. Microstructural, mechanical and acoustic emission-assisted wear characterization of equal channel angular pressed (ECAP) low stacking fault energy brass. Tribology International. 2018;123:273-85.

[28] Moshkovich A, Perfilyev V, Lapsker I, Feldman Y, Rapoport L. Study of the transition from EHL to BL regions under friction of $\mathrm{Ag}$ and $\mathrm{Ni}$. I. Analysis of acoustic emission. Tribology International. 2017;113:189-96.

[29] Taura H, Nakayama K. Behavior of acoustic emissions at the onset of sliding friction. Tribology International. 2018;123:155-60.

[30] Maia LHA, Abrao AM, Vasconcelos WL, Sales WF, Machado AR. A new approach for detection of wear mechanisms and determination of tool life in turning using acoustic emission. Tribology International. 2015;92:519-32.

[31] Hase A, Wada M, Mishina H. Scanning electron microscope observation study for identification of wear mechanism using acoustic emission technique. Tribology International. 2014;72:51-7.

[32] Hase A, Mishina H, Wada M. Correlation between features of acoustic emission signals and mechanical wear mechanisms. Wear. 2012;292:144-50.

[33] Saeidi F, Shevchik SA, Wasmer K. Automatic detection of scuffing using acoustic emission. Tribology International. 2016;94:112-7.

[34] Shevchik SA, Saeidi F, Meylan B, Wasmer K. Prediction of Failure in Lubricated Surfaces Using Acoustic Time-Frequency Features and Random Forest Algorithm. Ieee Transactions on Industrial Informatics. 2017;13:1541-53.

[35] Baccar D, Soffker D. Wear detection by means of wavelet-based acoustic emission analysis. Mechanical Systems and Signal Processing. 2015;60-61:198-207.

[36] Kalogiannakis G, Quintelier J, De Baets P, Degrieck J, Van Hernelrijck D. Identification of wear mechanisms of glass/polyester composites by means of acoustic emission. Wear. 2008;264:235-44.

[37] Zuo L, Zuo D, Zhu Y, Wang H. Acoustic emission analysis for tool wear state during friction stir joining of SiCp/Al composite. The International Journal of Advanced Manufacturing Technology. 2018;99:1361-8.

[38] Yin Y, Huang W, Liu X, Liu Y, Wang Z, Fan W, et al. Analysis of the Dynamic Friction of a Gas Face Seal Based on Acoustic Emissions. Tribology Letters. 2018;66:85.

[39] Borghesani P, Smith WA, Zhang X, Feng P, Antoni J, Peng Z. A new statistical model for acoustic emission signals generated from sliding contact in machine elements. Tribology International. 2018;127:412-9.

[40] James DR, Carpenter SH. Relationship between acoustic emission and dislocation kinetics in crystalline solids. Journal of Applied Physics. 1971;42:4685-+.

[41] Kiesewetter N, Schiller P. The acoustic emission from moving dislocations in aluminium. Physica status solidi (a). 1976;38:569-76.

[42] Khanna AS, Jha BB, Raj B. Detection of breakaway oxidation and spalling in the oxide scales of 21/4Cr-1Mo steel using acoustic emission technique. Oxidation of Metals. 1985;23:159-76. 
[43] Christl W, Rahmel A, Schutze M. Application of the acoustic emission technique for the detection of oxide scale cracking during thermal cycling. Materials Science and Engineering. 1987;87:289-93.

[44] Shankar NR, Berndt CC, Herman H, Rangaswamy S. Acoustic emission from thermally cycled plasma-sprayed oxides. American Ceramic Society Bulletin. 1983;62:614-9. 